\title{
A NOTE ON SECULAR CHANGES IN THE HUMAN SEX RATIO AT BIRTH
}

BY

\author{
C. R. LOWE and THOMAS MCKEOWN
}

From the Department of Social Medicine, University of Birmingham

Investigations of secular changes in the live-birth sex ratios of different countries have given conflicting results (Gini, 1908; Russell, 1936; Ciocco, 1938; Strandskov, 1942; Martin, 1943). In general the data are unsatisfactory, either because numbers of births are small, or because of inaccuracies and deficiencies in birth notification. Russell (1936) examined statistics for England and Wales, and drew attention to the decline of the sex ratio of live births between 1841-45 and 1896-1900, and to the sharp rise during and immediately after the 1914-18 war.

Changes in the sex ratio of live births may be due to one or both of two causes:

(a) changes in the ratio at conception (about which we have no direct evidence);

(b) changes in the losses experienced by the two sexes during intra-uterine life.

It is, of course, well recognized that the incidence of abortions and stillbirths (of which observed sex ratios are usually higher than of live births) influences the sex ratio of live births; it has not perhaps been sufficiently appreciated that sex ratios of stillbirths (and presumably of abortions also) are not constant. For example, the sex ratio of stillbirths varies with maternal age and duration of gestation, and it has been shown that part of this variation is due to changes in their composition (Lowe and McKeown, 1950; McKeown and Lowe, 1951). This suggests a possible explanation for the observed changes in the sex ratio of live births in association with other variables (such as birth rank, nationality, and social class) with which alterations may be anticipated in composition as well as in incidence of stillbirths and abortions.

We here examine secular changes in the sex ratio of live births from this viewpoint, using National Statistics for England and Wales and for Scotland. Fig. 1 exhibits quinquennial live-birth sex ratios* for England and Wales and for Scotland from the time registration was introduced (1841 and 1855 respectively) until 1946. In England and Wales the trend until 1930 is as described by Russell (1936); since 1930 the ratio has increased in each quinquennium. The Scottish sex ratio, though less regular, exhibits similar changes. These secular differences are small, but in view of the large numbers of births are highly significant. To decide whether secular changes in the live-birth sex ratio are due to changes in the losses experienced by the two sexes during intra-uterine life we should require complete records of

\footnotetext{
* The sex ratio is expressed as the percentage of males $\left(\begin{array}{c}M+F \\ M+F\end{array} \times 100\right.$.
} 


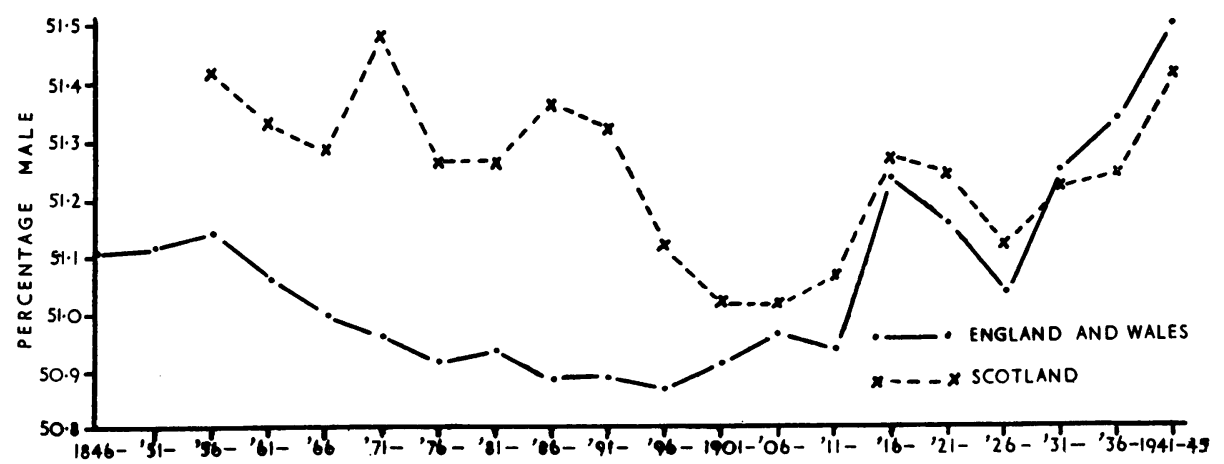

Fig. 1.-Quinquennial live-birth sex ratio (England and Wales, 1846-1945; Scotland, 1856-1945).

abortions and stillbirths. We have, of course, no such information, but we can examine the infant mortality rate over the same period (Fig. 2). It will be seen that the infant mortality rate is roughly inversely related to the sex ratio of live births (Fig. 1), and it seems reasonable to suppose that the same is also true of the incidence of abortions and stillbirths. This may explain the secular trend of the live-birth sex ratio. The fluctuation in the live-birth sex ratio observed in many countries during and immediately after the 1914-18 war is unexplained. It may be noted, however, that reproductive habits are disturbed by a protracted war: absence of husbands prolongs the interval between legitimate maternities; the number of illegitimate births is increased; the mean age at marriage falls; and there are relatively more first births. These changes must certainly influence the incidence and composition of abortions and stillbirths, and hence may account for the sharp rise in the sex ratio of live births.

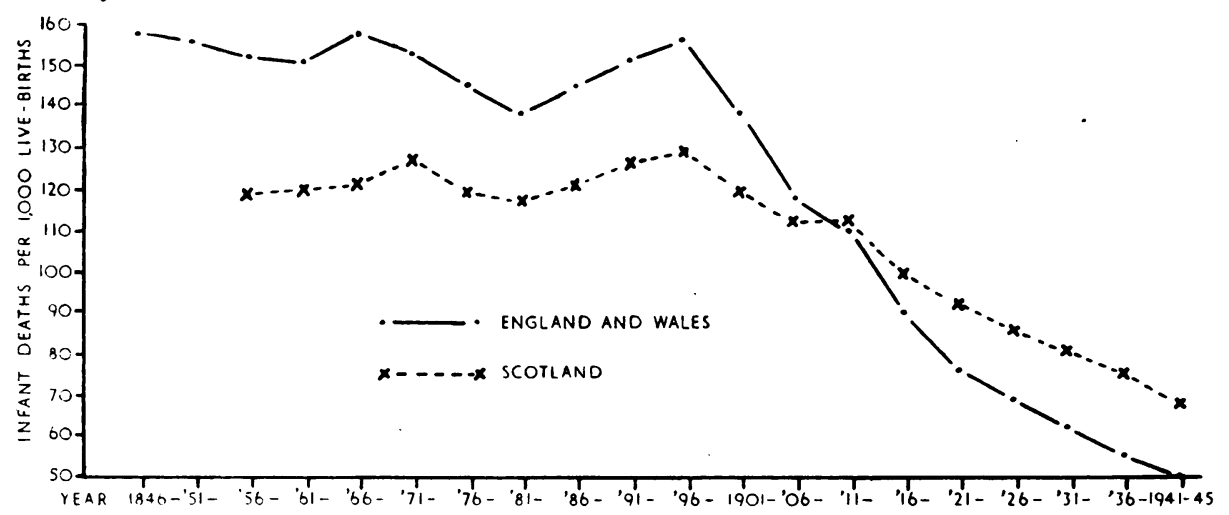

Fig. 2.-Quinquennial infant mortality rate (England and Wales, 1846-1945; Scotland, 1856-1945).

The proportion of males among illegitimate births is generally stated to be lower than among related legitimate births (Heape, 1909; De Jastrzebski, 1919; Russell, 1936). In England and Wales over the period 1851-1945, however, the 
sex ratio of illegitimate live births has been slightly but significantly higher than that of related legitimate births (Table I and Fig. 3). This can only be explained by a lower sex ratio of the abortions and stillbirths (unless we assume a difference in the sex ratios at conception) since abortion and stillbirth rates are undoubtedly higher in illegitimate pregnancies. Certainly some difference in the sex ratios of abortions and stillbirths would be expected, since their incidence and composition are different in legitimate and illegitimate pregnancies. (For example, procured abortion is much commoner in illegitimate pregnancy.)

TABLE I

Sex Ratio of Legitimate and Illegitimate Live Births England and Wales 1851-1945

\begin{tabular}{|c|c|c|c|c|c|}
\hline \multirow{2}{*}{\multicolumn{2}{|c|}{ Type of Birth }} & \multicolumn{2}{|c|}{ No. of Live Births } & \multirow{2}{*}{ Sex Ratio } & \multirow{2}{*}{$\begin{array}{l}\text { Difference } \\
(a)-(b)\end{array}$} \\
\hline & & Total & Male only & & \\
\hline Illegitimate & . & $3,668,297$ & $1,874,873$ & $51 \cdot 110(a)$ & \multirow{2}{*}{$+0.076 \pm 0.027$} \\
\hline Legitimate & .. & $70,871,982$ & $36,168,734$ & $51 \cdot 034(b)$ & \\
\hline
\end{tabular}

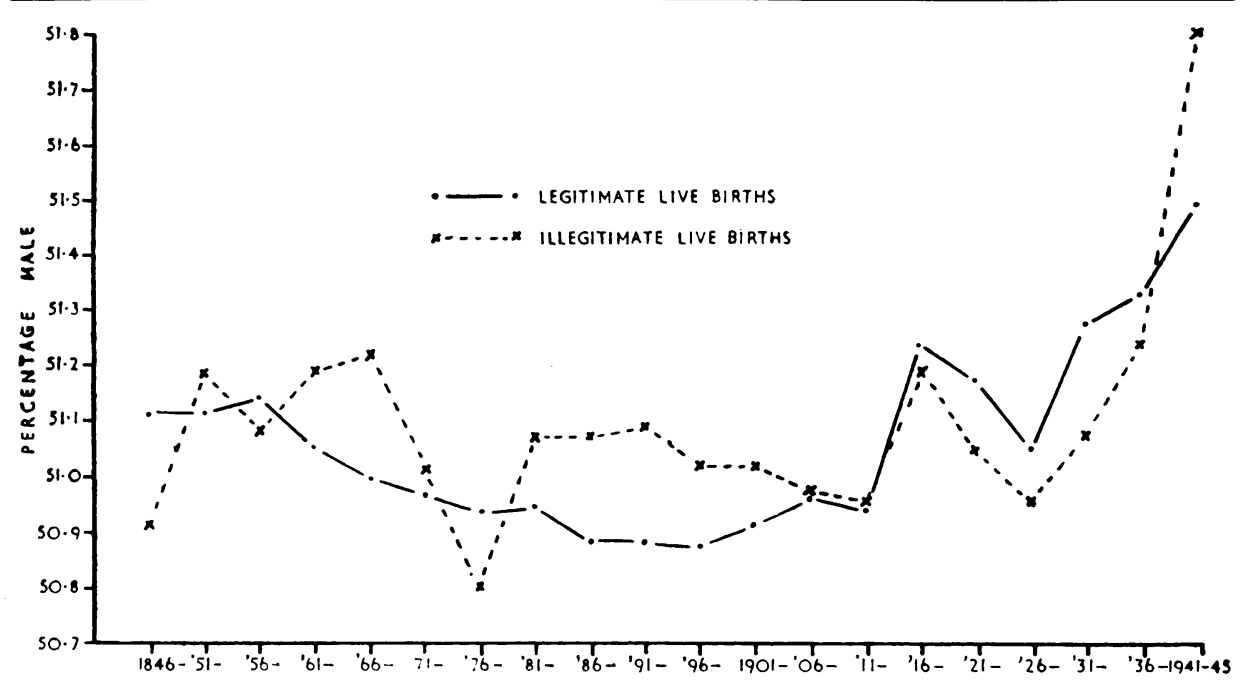

FIG. 3.-Quinquennial legitimate and illegitimate live-birth sex ratio (England and Wales, 1846-1945).

\section{Secular Changes in the Stillbirth Sex Ratio}

During the short period of stillbirth registration (since 1928 in England and Wales, and since 1939 in Scotland) the stillbirth sex ratios have decreased (Tables II and III). On Scottish data it is possible to explore this change in relation to cause of stillbirth, and Table IV gives sex ratios for each of the four main classes used by the Registrar-General. It will be observed that with one exception 
TABLE II

Secular Trend of Stillbirth and Live-Birth Sex Ratios

(England and Wales 1928-1947)

\begin{tabular}{|c|c|c|c|c|c|c|c|c|c|c|}
\hline Year & $1928-29$ & $1930-31$ & $1932-33$ & $1934-35$ & $1936-37$ & 1938-39 & $1940-41$ & $1942-43$ & . $1944-45$ & $1946-47$ \\
\hline $\begin{array}{l}\text { No. of Stillbirths } \\
\text { Stillbirth Sex Ratio } \\
\text { No. of Live Births } \\
\text { Live-BirthSexRatio }\end{array}$ & $\begin{array}{c}30,060 \\
55 \cdot 2 \\
1,303,940 \\
51 \cdot 06\end{array}$ & $\begin{array}{c}30,192 \\
55 \cdot 4 \\
1,280,892 \\
51 \cdot 13\end{array}$ & $\begin{array}{c}28,099 \\
54 \cdot 5 \\
1,194,385 \\
51 \cdot 17\end{array}$ & $\begin{array}{c}27,480 \\
54 \cdot 3 \\
1,196,398 \\
51 \cdot 36\end{array}$ & $\begin{array}{c}27,118 \\
54 \cdot 4 \\
1,215,849 \\
51 \cdot 34\end{array}$ & $\begin{array}{c}26,437 \\
53 \cdot 9 \\
1,235,683 \\
51 \cdot 31\end{array}$ & $\begin{array}{c}23,564 \\
54 \cdot 0 \\
1,169,211 \\
51 \cdot 29\end{array}$ & $\begin{array}{c}23,337 \\
53 \cdot 5 \\
1,335,837 \\
51 \cdot 55\end{array}$ & \begin{tabular}{|c|}
21,860 \\
$53 \cdot 8$ \\
$1,431,415$ \\
$51 \cdot 54$
\end{tabular} & $\begin{array}{c}24,149 \\
54 \cdot 0 \\
1,701,745 \\
51 \cdot 47\end{array}$ \\
\hline
\end{tabular}

TABLE III

Secular Trend of Stillbirth and Live-Birth Sex Ratios (Scotland 1940-1947)

\begin{tabular}{l|c|c|c|c}
\hline \multicolumn{1}{c|}{..} & $1940-41$ & $1942-43$ & $1944-45$ & $1946-47$ \\
\hline Year & 7,489 & 7,093 & 6,163 & 7,038 \\
\hline $\begin{array}{l}\text { No. of Stillbirths } \\
\text { Stillbirth Sex Ratio }\end{array}$ & $55 \cdot 8$ & $53 \cdot 4$ & $52 \cdot 9$ & $52 \cdot 9$ \\
No. of Live Births & 176,146 & 185,379 & 182,873 & 217,560 \\
Live-Birth Sex Ratio & $51 \cdot 32$ & $51 \cdot 21$ & $51 \cdot 60$ & $51 \cdot 43$ \\
\hline
\end{tabular}

TABLE IV

Secular Trend of Stillbirth Sex Ratio Related to Cause of Stillbirth (Scotland 1940-1947)

\begin{tabular}{|c|c|c|c|c|c|}
\hline Cause of Stillbirth & $1940-41$ & $1942-43$ & $1944-45$ & $1946-47$ & $1940-47$ \\
\hline Disease in or accident to the mother & $\begin{array}{c}58 \cdot 5 \\
(2,007)^{*}\end{array}$ & $\begin{array}{c}56 \cdot 5 \\
(1,977)\end{array}$ & $\begin{array}{c}57 \cdot 9 \\
(1,561)\end{array}$ & $\begin{array}{c}55 \cdot 9 \\
(1,804)\end{array}$ & $\begin{array}{c}57 \cdot 2 \\
(7,349)\end{array}$ \\
\hline Anomalies of foetus, placenta, or cord & $\begin{array}{c}44 \cdot 5 \\
(1,579)\end{array}$ & $\begin{array}{c}41 \cdot 4 \\
(1,740)\end{array}$ & $\begin{array}{c}42 \cdot 5 \\
(1,669)\end{array}$ & $\begin{array}{c}43 \cdot 2 \\
(1,866)\end{array}$ & $\begin{array}{c}42 \cdot 9 \\
(6,854)\end{array}$ \\
\hline $\begin{array}{l}\text { Death of foetus by injury or other } \\
\text { cause }\end{array}$ & $\begin{array}{c}61 \cdot 9 \\
(1,915)\end{array}$ & $\begin{array}{c}59 \cdot 5 \\
(2,112)\end{array}$ & $\begin{array}{c}57 \cdot 8 \\
(1,902)\end{array}$ & $\begin{array}{c}58 \cdot 0 \\
(2,194)\end{array}$ & $\begin{array}{c}59 \cdot 3 \\
(8,123)\end{array}$ \\
\hline Ill-defined and unknown causes & $\begin{array}{c}56 \cdot 2 \\
(1,988)\end{array}$ & $\begin{array}{c}55 \cdot 1 \\
(1,264)\end{array}$ & $\begin{array}{c}53 \cdot 1 \\
(1,031)\end{array}$ & $\begin{array}{c}53 \cdot 8 \\
(1,174)\end{array}$ & $\begin{array}{c}54 \cdot 8 \\
(5,457)\end{array}$ \\
\hline All Causes & $\begin{array}{c}55 \cdot 8 \\
(7,489)\end{array}$ & $\begin{array}{c}53 \cdot 4 \\
(7,093)\end{array}$ & $\begin{array}{c}52 \cdot 9 \\
(6,163)\end{array}$ & $\begin{array}{c}52 \cdot 9 \\
(7,038)\end{array}$ & $\begin{array}{c}53 \cdot 8 \\
(27,783)\end{array}$ \\
\hline
\end{tabular}

* Numbers of stillbirths (male and female) given in brackets.

(anomalies of foetus, placenta, or cord) sex ratios of the individual classes have declined. (The proportionate contribution of each class to the total number of stillbirths has also changed, and this has had a slight effect on the sex ratio.)

The sex ratio of stillbirths (all causes), or of any class of stillbirth, depends, of course, upon:

(a) relative stillbirth rates of males and females;

(b) the numbers of foetuses of each sex in the uterus.

Sex specific rates are given for England and Wales and for Scotland in Tables 
TABLE $\mathrm{V}$

Secular Trend of Sex Specific Stillbirth Rates (England and Wales 1928-1947)

\begin{tabular}{|c|c|c|c|c|c|c|c|c|c|c|c|}
\hline Year & $\ldots$ & 1928-29 & $1930-31$ & $1932-33$ & 1934-35 & 1936-37 & 1938-39 & $91940-41$ & $1942-43$ & $\begin{array}{lll}3 & 1944-45\end{array}$ & $1946-47$ \\
\hline \multirow{2}{*}{$\begin{array}{l}\text { Still- } \\
\text { birth } \\
\text { Rate* }\end{array}$} & Male & $43 \cdot 2$ & $44 \cdot 1$ & $44 \cdot 0$ & $42 \cdot 8$ & $41 \cdot 6$ & $40 \cdot 0$ & $37 \cdot 8$ & $32 \cdot 8$ & $28 \cdot 8$ & $26 \cdot 8$ \\
\hline & F'male & $36 \cdot 8$ & $37 \cdot 4$ & $38 \cdot 7$ & $38 \cdot 3$ & $37 \cdot 0$ & $36 \cdot 2$ & $34 \cdot 1$ & $30 \cdot 4$ & $26 \cdot 4$ & $24 \cdot 3$ \\
\hline
\end{tabular}

* Sex specific stillbirth rates expressed as number of stillbirths per thousand related total births.

TABLE VI

Secular Trend of Sex Specific Stillbirth Rates Related to Cause of Stillbirth (Scotland 1940-1947)

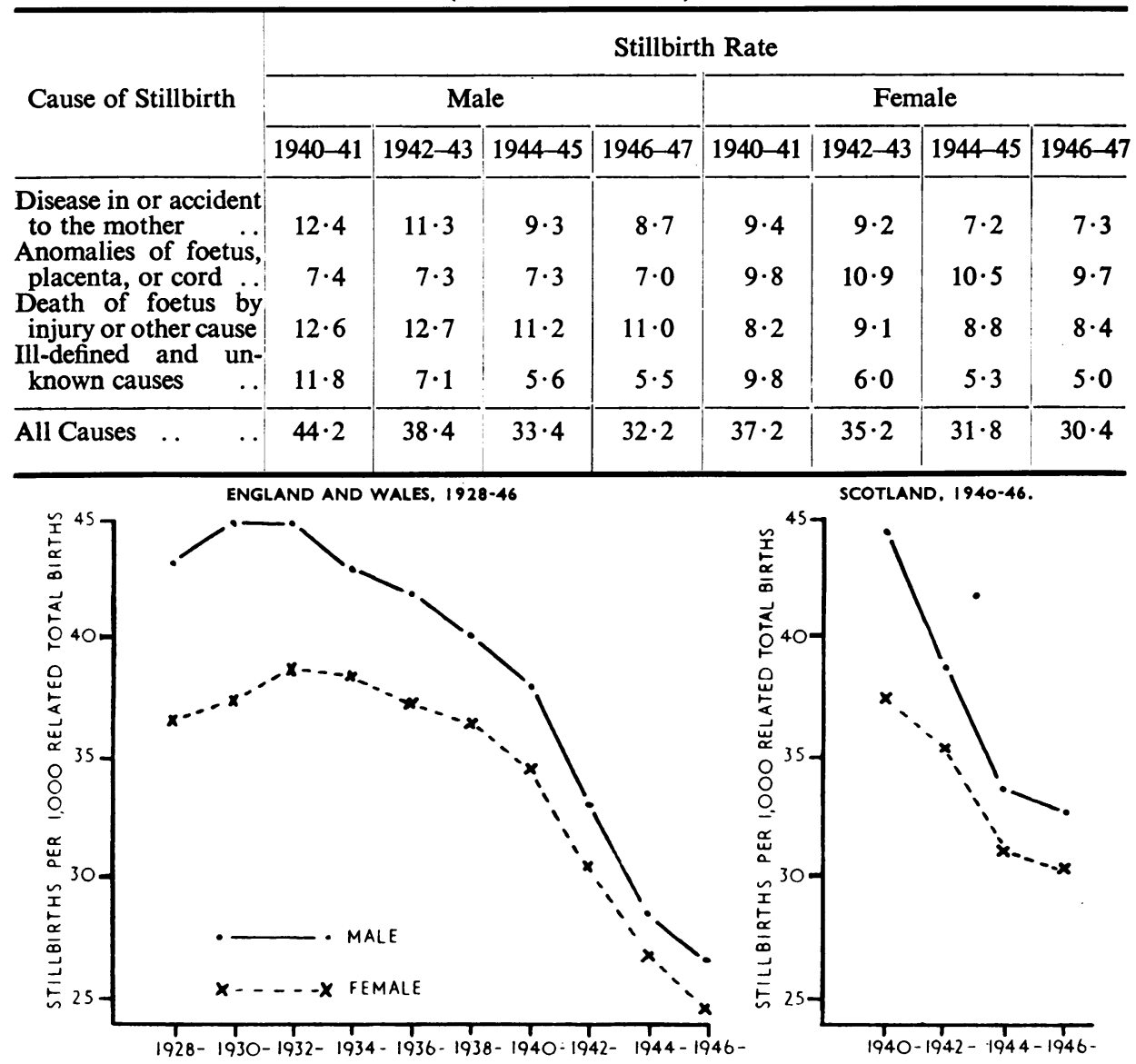

Fig. 4.-Sex-specific stillbirth rates.

V and VI respectively (see also Fig. 4). It will be noted that:

(i) the stillbirth rates of both sexes have been reduced since notification began;

(ii) the decrease has been relatively greater for males, so that the difference between the two sexes has been reduced. 
Table VI (Fig. 5) also gives sex specific stillbirth rates for each of the four main classes of stillbirth (Scottish data). In one class (anomalies of foetus, placenta, or cord) the rates have been almost constant; in the other three classes the rates for the two sexes exhibit the changes already noted ((i) and (ii)) for all stillbirths.
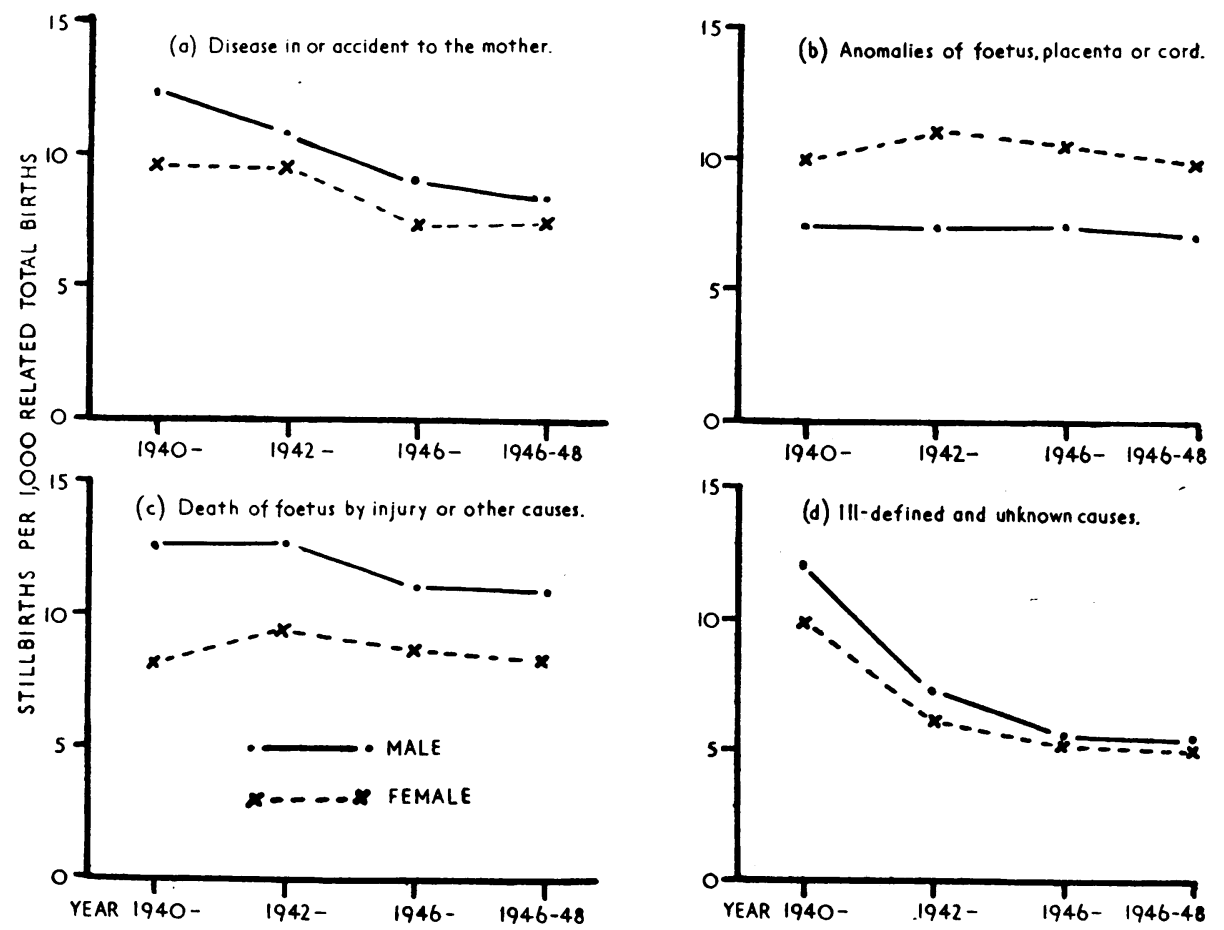

Fig. 5.-Sex-specific stillbirth rates related to cause of stillbirth (Scotland, 1940-1947).

\section{CoNCLUSIONS}

It is suggested that alterations in the composition and incidence of abortions and stillbirths may explain variation in the live-birth sex ratio reported in association with birth rank, maternal age, duration of gestation, and social class. Since the incidence of abortions is much greater than the incidence of stillbirths, it is not surprising that no close correlation has been observed between the incidence and sex ratio of stillbirths and the live-birth sex ratio. It can be shown, however, that the composition of stillbirths has a considerable effect upon their sex ratio, and it is reasonable to suppose that the same is true of abortions.

During the short period of stillbirth registration (England and Wales and Scotland) the stillbirth sex ratio has decreased. It is shown that

(i) the stillbirth rates of both sexes have decreased;

(ii) the decrease has been relatively greater for males. 
Examination of sex ratios of four classes of stillbirth (Scotland) indicates that three classes exhibit the changes already noted $((i)$ and $(i i))$, whereas in the fourth class (that with the lowest sex ratio) stillbirth rates for both males and females have remained almost constant.

If abortions, like stillbirths, also vary from year to year in composition and incidence, the small but significant secular variation observed in the live-birth sex ratio may be due to these changes.

Ciocco, A. (1938). Hum. Biol., 10, 36.

\section{REFERENCES}

de Jastrzebski, S. (1919). Eugen. Rev., 11, 7.

Gini, C. (1908). "Il sesso dal punto di vista statistico ". Remo Sandron, Milan.

Heape, W. (1909). Proc. roy. Soc. (B), 81, 32.

Lowe, C. R., and McKeown, T. (1950). British Journal of Social Medicine, 4, 75.

Martin, W. J. (1943). Lancet, 2, 807.

McKeown, T., and Lowe, C. R. (1951). Hum. Biol., 23, 41.

Russell, W. T. (1936). J. Hyg., Camb., 36, 381.

Strandskov, H. H. (1942). Hum. Biol., 14, 85. 